\title{
Aspectos culturais, morfológicos e morfométricos de Sordaria fimicola incidente em folhas de capim-massambará (Sorghum arundinaceum)
}

\author{
Andressa de Souza Almeida ${ }^{1}$, Marcos Antônio Garcia Caetano da Costa ${ }^{1}$, Lucinete Martins \\ Barbosa Estrela ${ }^{1}$, Milton Luiz da Paz Lima ${ }^{1}$
}

${ }^{1}$ Instituto Federal Goiano, Campus Urutaí, Urutaí, Goiás, Brasil. E-mail: andressa.s.almeida@live.com, marcos4ntonio@outlook.com, luestrela.bio@gmail.com, fitolima@gmail.com

Recebido: 11/01/2017; Aceito: 25/01/2019.

\begin{abstract}
RESUMO
O capim-massambará (Sorghum arundinaceum) pode servir de fonte de inóculo de agentes de biocontrole como Sordaria spp. O objetivo deste trabalho foi avaliar o crescimento in vitro, a patogenicidade, caracterizar e identificar um isolado de Sordaria sp. incidente em capim-massambará. Amostras de folhas apresentando sintomas foram submetidas a isolamento em meio de cultura. A partir deste foram aplicados os seguintes testes: a) teste fisiológico - análise do crescimento micelial em meio de cultura. b) teste biológico - discos de micélio e solução de ascósporos foram inoculados em folhas; e c) identificação - caracterização morfológica das estruturas reprodutivas. O maior crescimento micelial foi observado nos meios BDA e ST. O isolado em condições artificiais não reproduziu os sintomas iniciais. $\mathrm{O}$ isolado apresentou peritécio gregário, semi-imerso em meio de cultura, sub-globoso, com organização celular reticulada, de dimensões de 1946,3-(1351,0)-507,9 × 1131,4(828,2)-415,17 $\mu \mathrm{m}$, com ostíolo de 413,85-(257,8)-123,8 $\mu \mathrm{m}$; asca cilíndrica à clavada, unitunicada, de 195,0(167,8)-135,6 × 21,8-(16,8)-9,1 $\mu \mathrm{m}$; ascósporos apresentaram 29,7-(22,6)-13,7 × 14,9-(10,9)-1,6 $\mu \mathrm{m}$. Com base nas características morfológicas e morfométricas, o isolado foi identificado como sendo $S$. fimicola.
\end{abstract}

Palavras-chave: Ascomycota, micologia, fisiologia de crescimento, taxonomia de fungos.

\section{Cultural, morphological and morphometric ascpects of the Sordaria fimicola in leaves of massambara grass (Sorghum arundinaceum)}

\begin{abstract}
Johnson grass (Sorghum arundinaceum) can serve as an inoculum source of biocontrol agents such as Sordaria spp. The objective of this work was to evaluate the in vitro growth, pathogenicity, characterize and identify an isolate of Sordaria sp. incident in Johnson grass. Samples of leaves showing symptoms were submitted to isolation in culture medium. The following tests were applied: a) Physiological test - analysis of mycelial growth in culture medium. b) Biological test - mycelial discs and ascospores solution were inoculated in leaves; and c) Identification - morphological characterization of reproductive structures. The highest mycelial growth was observed in the BDA and ST media. The isolate under artificial conditions did not reproduce the initial symptoms. The isolate presented a gregarious perithecium, semi-immersed in sub globular culture medium, with reticulated cell organization, of dimensions of 1946.3-(1351.0)-507.9 × 1131.4- (828.2)-415.17 $\mu \mathrm{m}$, with ostium of 413.85(257.8)-123.8 $\mu \mathrm{m}$; 195.8-(167.8)-135.6 × 21.8-(16.8)-9.1 $\mu \mathrm{m}$; ascospores presented 29.7-(22.6)-13.7 × 14.9(10.9)-1.6 $\mu \mathrm{m}$. Based on the morphological and morphometric characteristics, the isolate was identified as $S$. fimicola.
\end{abstract}

Keywords: ascomycota, mycology, growth physiology, fungi taxonomy. 


\section{Introdução}

O capim-massambará ou sorgo-selvagem (Sorghum arundinaceaum - Poaceae) é uma planta espontânea ocorrente no Brasil, que botanicamente assemelha-se ao sorgo cultivado, representando na natureza uma ampla relação biológica que pode ter como consequência o reservatório de agentes de biocontrole como Sordaria spp. (Chandramohan e Charudattan, 2001).

Lorenzi e Matos (2008) apontaram que se trata de uma planta originária da África, também conhecida como sorgo-selvagem ou falso-massambará, considerada daninha e/ou infestante mediamente frequente em quase todo o país. É uma espécie anual ou perene, herbácea, cespitosa, ereta, que infesta principalmente lavouras perenes, cafezais, beira de estradas e terrenos baldios, de introdução recente e que vem aumentando em sua área infestada ano após ano. É ocasionalmente utilizada como forrageira. Apresenta colmos com até $1 \mathrm{~cm}$ de diâmetro e entrenós de 18-20 $\mathrm{cm}$ de comprimento, com 1,5-2,5 m de altura, propagase exclusivamente por meio de sementes.

É frequentemente confundida com o S. halepense, entretanto, este é perene, rizomatoso e de porte menor que o capim-massambará. Chiang et al. (1989) identificaram quatro fungos fitopatogênicos (Exserohilum turcicum, Colletotrichum graminicola, Gloeocercospora sorghi e Bipolaris halepense) capazes de controlar plântulas desta espécie espontânea de sorgo.

Pelo fato de ser uma planta daninha que pode hospedar patógenos, estes podem se apresentar emergentes e bastante devastadores às plantas cultivadas, visto que as formas sexuais de fitopatógenos representam a incidência de um ciclo com máxima variabilidade e ampliação do potencial adaptativo de Sordaria sp. (Agrios, 1997).

Doguet (1960) apontou que o núcleo de algumas espécies iniciam o processo de formação e de crescimento da hifa, que se divide por mitoses típicas. E tem sido observada a presença de equinulações de 1,5 a $3 \mu \mathrm{m}$ de comprimento, que têm orientações seguidas para vários sentidos de acordo com a largura da hifa. A espécie S. fimicola é um fungo homotálico e sua fase anamórfica produz tanto conídios quanto microconídios, reproduzindo-se sexualmente através de ascósporos que são liberados através da abertura ostiolar do peritécio.

Curiosamente foi apontado que detalhes do desenvolvimento do peritécio não foram completamente elucidados, exatamente como a plasmogamia se desenvolve (Greis, 1936). Greis (1942) registrou o contato entre os gametângios representados por ascogônios e anterídio; Ritchie (1937) e Carr e Olive (1958) demonstraram a fusão de hifas entre dois isolados e a fusão nuclear de uma para outra. A provável somatogamia opera como o principal método de reprodução sexual ou o simples contato entre os gametângios e a produção de fungos periteciais pode ocorrer abundantemente quando ocorre uma supressão de carboidratos tornando desfavorável o crescimento vegetativo (Alexopoulos e Mims, 1979).

Em pH acima de 6 e a presença de biotina e tiamina, observou-se a produção de peritécios e maturação de ascos. Contudo, a concentração de biotina é pouca, com relação ao estímulo à produção de peritécio de $S$. fimicola e outros ascomicetos formados. Quando adultos, pode ocorrer a supressão da formação de ascos, impedindo a formação de ascósporos (Alexopoulos e Mims, 1979).

Há uma formação direta entre a formação de biotina e o surgimento de ascósporos produzidos (Barnett e Lilly, 1947). O processo de liberação de ascósporos por muitos ascomicetos e os fungos periteciais pertencentes ao gênero Sordaria sp. são extremamente influenciados pela luz (Ingold e Cox, 1955; Ingold, 1956).

Os ascos maduros, quando estão aptos, liberam estes ascósporos através da abertura peritecial (ostíolo); alguns ascos são liberados pela abertura ostiolar (Alexopoulos e Mims, 1979). Os ascósporos de Sordaria sp. não ficam confinados no peritécio, eles têm um método de liberação que pode ser um padrão desenvolvido para vários membros pertencentes a diferentes gêneros e famílias de ascomicetos. Muitos dos ascósporos são liberados e germinam produzindo micélio em condições favoráveis (Alexopoulos e Mims, 1979).

Em trabalhos de citologia e genética para fungos homotálicos, têm sido observadas interessantes mutações em S. fimicola, que produzem ascósporos laranja-acinzentados a marrons escuros (sendo observado em cepas selvagens). Estes mutantes crescem junto aos selvagens, obtendo e produzindo peritécios com ascos heterotálicos, contendo ambas as características (Olive, 1956). O uso de fungos para controle biológico e/ou uso como bioherbicida tem sido bastante apontado em literatura para diferentes espécies invasoras de campos agrícolas (Zhang e Watson, 1997a; Zhang et al., 1996).

O objetivo deste trabalho foi realizar uma análise comparativa de aspectos biológicos, morfológicos e morfométricos de Sordaria sp. incidentes em folhas de capim-massambará (Sorghum arundinaceum).

\section{Material e Métodos}

Amostras de folhas capim-massambará apresentando sintomas de manchas foliares foram coletadas na cidade de Urutaí, GO. Estas folhas foram submetidas a isolamento em cultivo artificial, produzindo uma cultura pura do ascomiceto Sordaria sp. O trabalho foi realizado seguindo as etapas abaixo: 


\subsection{Teste biológico}

Antes da inoculação, as folhas de capimmassambará foram cultivadas em vasos de $2 \mathrm{~L}$ de solo e submetidas à assepsia superficial (borrifagem de álcool [50\%], hipoclorito de sódio ( $\mathrm{HClO}[0,3 \%]$ ) e três vezes de água destilada). Em seguida, as folhas foram secas com a utilização de um papel absorvente, colocadas em uma vasilha de plástico com tampa e levadas para câmara de fluxo laminar, onde foram perfuradas com a ajuda de uma agulha estéril.

Os tratamentos com ferimento foram realizados através da inoculação de discos de micélio na área perfurada. Além desses, foram inoculados discos de micélio em folhas não perfuradas. Após a inoculação, as folhas foram pulverizadas com água destilada $\mathrm{e}$ mantidas em condições de saturação máxima de umidade. A vasilha que continha as mudas foi tampada e deixada dentro da câmara de crescimento por um período de 7-10 dias até a avaliação da expressão de sintomas. Esta inoculação foi realizada três vezes.

Além do disco de micélio, inocularam-se suspensões de esporos, sendo realizadas a partir de uma placa de Petri contendo uma cultura de Sordaria fimicola de sete dias, adicionando-se a placa por volta de $10 \mathrm{~mL}$ de água destilada estéril, pincelando-se a superfície da cultura a fim de que os ascósporos misturassem a suspensão. Esta foi filtrada com gaze e quantificada utilizando câmara de Neubauer, produzindo uma solução na concentração de $10^{4}$ ascósporos $\mathrm{mL}^{-1}$, que foi pulverizada em folhas de capim-massambará sadio e cultivada em vaso previamente submetido à assepsia superficial. Após a inoculação, as amostras de folha permaneceram em condições de saturação máxima de umidade por um período de 7-10 dias. Esta metodologia adaptada pode ser observada em Alfenas e Mafia (2007). Descreveramse os sintomas na planta original e nas plantas inoculadas.

\subsection{Teste fisiológico de crescimento cultural}

Foram preparados cinco meios para cultivo de S. fimicola, sendo suas receitas representadas pelos seguintes ingredientes: (AA) $10 \mathrm{~g}$ de ágar e $250 \mathrm{~mL}$ de água destilada; (ST) $250 \mathrm{~mL}$ de água destilada, $62,5 \mathrm{~mL}$ de suco-de-tomate, $0,93 \mathrm{~g}$ de carbonato de cálcio e 5,6 $\mathrm{g}$ de ágar; (BDA) $50 \mathrm{~g}$ de batata descascada, $5 \mathrm{~g}$ de dextrose, $4 \mathrm{~g}$ de ágar e $300 \mathrm{~mL}$ de $\mathrm{H}_{2} \mathrm{O}$ destilada; (NE) $25 \mathrm{mg}$ de azul de bromofenol, $25 \mathrm{mg}$ de cloranfenicol e $28 \mathrm{mg}$ de manitol; (NA) $7 \mathrm{~g}$ de ágar nutritivo e $250 \mathrm{~mL}$ de água destilada. Todos os solutos foram dissolvidos na quantidade de água destilada necessária para cada receita (exceto no meio BDA, em que a batata foi cozida em água destilada e o caldo foi misturado aos ingredientes sólidos) em um Erlenmeyer, e, em seguida colocados na autoclave para a esterilização, na temperatura de $120^{\circ} \mathrm{C}$ por $20^{\prime}$, para que depois do esfriamento fossem vertidos em placas de Petri em câmara de fluxo laminar.

Foi adicionado um disco de micélio, retirado da cultura matriz de S. fimicola, oriundo de manchas foliares, e colocado sob os cinco meios acima descritos. Utilizou-se no ensaio cinco tratamentos (tipos de meios de cultivo) e duas repetições, num delineamento inteiramente casualizado. As placas vedadas permaneceram incubadas a $25^{\circ} \mathrm{C}$ sob regime de fotoperíodo de 12 horas. O diâmetro da colônia (mm) foi avaliado diariamente com o auxílio de uma régua, até que as colônias atingissem as bordas das placas. Este ensaio foi realizado três vezes.

A partir do diâmetro de colônia temporal, calculouse a taxa de crescimento micelial (TC) e a área abaixo da curva de progresso do crescimento micelial (AACPCM), sendo submetidas ao teste $\mathrm{F}$ e ao teste de Skott Knott $(\mathrm{P} \leq 0,05)$. As médias do crescimento micelial foram plotadas graficamente, gerando curvas de crescimento que foram ajustadas ao modelo linear, gerando equações de ajuste e o coeficiente de determinação $\left(\mathrm{R}^{2}\right)$.

\subsection{Caracterização morfológica e morfométrica do isolado}

As folhas de capim-massambará foram exsicatadas e analisadas em microscópio estereoscópico. Os propágulos foram transferidos para lâminas contendo fixador (2,6 mL ácido acético, 62,5 mL ácido lático, 100 $\mathrm{mL}$ de glicerina e $100 \mathrm{~mL}$ de água destilada) diluído com corante azul-de-algodão. Em seguida, realizou-se corte histológico para visualização em microscópio óptico. As estruturas observadas no microscópio foram comparadas com estruturas descritas (Tabela 1), reconhecidas em espécies de Sorghum spp. em literatura, e aquelas que apresentavam maior proximidade morfológica e morfométrica foram escolhidas neste trabalho (S. fimicola e S. macrospora).

No segundo procedimento para produção da cultura matriz, foi realizado um recorte no fragmento do tecido entre a região doente e sadia, que foi submetido à assepsia superficial. Em seguida, os fragmentos foram secos com papel mata borrão, sendo posteriormente plaqueados em meio de cultura AA.

Após 48 horas de incubação a $25^{\circ} \mathrm{C}$, discos de micélio foram repicados para meio de cultura BDA, também sob incubação a $25^{\circ} \mathrm{C}$ em fotoperíodo de $12 \mathrm{~h}$ de luz, por um período de 7-10 dias. As culturas foram fotografadas e suas características morfológicas avaliadas.

A partir de registro microfotográfico, foram preparadas lâminas semipermanentes para registro e morfometria das estruturas do patógeno, onde as folhas de capim-massambará foram exsicatadas e analisadas em microscópio estereoscópico. 
Tabela 1. Comparação do isolado de Urutaí (2016) reconhecido e identificado com espécies descritas mais próximas do isolado (nd. não determinado).

\begin{tabular}{|c|c|c|c|}
\hline $\begin{array}{l}\text { Características } \\
\text { morfológicas }\end{array}$ & Urutaí (2016) & $\begin{array}{l}\text { S. fimicola Roberge ex Desm. } \\
\text { Ces. \& De Not. (1963) }\end{array}$ & S. macrospora-Auersw. (1866) \\
\hline \multicolumn{4}{|l|}{ Peritécio } \\
\hline Forma & globoso, cônico a piriforme & sub-globoso & globoso \\
\hline Imersão no substrato & & semi-imerso $(1 / 5-1 / 4)$ & nd \\
\hline Agregação & gregário & gregário & nd \\
\hline $\begin{array}{l}\text { Forma do tecido } \\
\text { estromático }\end{array}$ & & membranáceo à coriáceo & Membranáceo \\
\hline Dimensões $(\mu \mathrm{m})$ & $\begin{array}{c}1946,3-(1351,0)-507,9 \times \\
1131,4-(828,2)-86,4\end{array}$ & nd & nd \\
\hline $\begin{array}{l}\text { Diâmetro do ostíolo } \\
\qquad(\mu \mathrm{m})\end{array}$ & $413,85-(257,8)-123,8$ & nd & nd \\
\hline Forma do rostro & $\begin{array}{l}\text { ausente ou conóideo, } \\
\text { espesso e curvo }\end{array}$ & conóideo, espesso e curvo & cônico a reto \\
\hline \multicolumn{4}{|l|}{ Asca } \\
\hline Forma & cilíndrica e rostrada & cilíndrica e rostrada & $\begin{array}{l}\text { tabulóide de ápice retuso- } \\
\text { truncado }\end{array}$ \\
\hline Dimensões $(\mu \mathrm{m})$ & $\begin{array}{c}195,0-(167,8)-135,6 \times 21,8- \\
(16,8)-9,1\end{array}$ & $100-150 \times 14-16$ & $280-360 \times 160-180$ \\
\hline \multicolumn{4}{|l|}{ Ascósporos } \\
\hline Forma & elipsóide a ovoide & ovoide & nd \\
\hline Número por asca & 8 & nd & 8 \\
\hline Organização & unisseriada & nd & unisseriada \\
\hline Dimensões $(\mu \mathrm{m})$ & $\begin{array}{c}29,7-(22,6)-13,7 \times 14,9- \\
(10,9)-1,6\end{array}$ & $17-20 \times 10-12$ & $36-28 \times 16-18$ \\
\hline Coloração & marrom-oliváceo & marrom-oliváceo & \\
\hline $\begin{array}{l}\text { Presença de } \\
\text { ornamentação }\end{array}$ & $\begin{array}{l}\text { ausente, presença de fenda } \\
\text { longitudinal e de núcleo } \\
\text { oleoso com centro hialino }\end{array}$ & núcleo oleoso com centro hialino & nd \\
\hline
\end{tabular}

Utilizando microscópio de captura digital, realizouse a morfometria de 100 unidades dos peritécios (dimensões C x L [comprimento - C, e largura - L]), asca (dimensões C x L) e ascósporos (dimensões C x L), além dos aspectos morfológicos observados e descritos (Tabela 1).

Macro e microfotografias descritivas das características morfológicas foram utilizadas para confecção de pranchas.

\section{Resultados e Discussão}

\subsection{Teste biológico}

O teste de patogenicidade não reconheceu Sorghum arundinaceum como hospedeiro de S. fimicola (isolado originalmente oriundo de manchas foliares). Artificialmente as inoculações de discos de micélio e suspensões de ascósporos, com e sem ferimentos, não expressaram sintomas.
Em relação aos sintomas inicialmente reconhecidos (Figura 1) classicamente, Panizzi et al. (2005) apontam como sendo agentes causais Bipolaris sp. (agente causal de helminthosporiose) e Colletotrichum sp. (agente causal de antracnose) em sorgo - Sorghum spp. (hospedeiro comercial mais conhecido e espécie vegetal mais próxima de $S$. arundinacearum). Chandramohan e Charudattan (2001) inocularam uma mistura de fungos representada por Drechslera gigantea, Exserohilum longirostratum e E. rostratum, todos agentes causais de helmintosporioses na concentração maior de $2 \times 10^{5}$ conídios $\mathrm{mL}^{-1}$, com objetivos de agirem como bioherbicidas, sendo uma importante estratégia antirresistência a herbicidas para plantas daninhas. O isolado obtido em condições artificiais não reproduziu os sintomas de mancha foliar em capim-massambará inicialmente descritos acima e pela Figura 1, mesmo após a repetição de três ensaios de inoculação, resultado contrário ao de Chandramoham e Charudattan (2001), 
que detectaram três candidatos para uso como bioherbicidas. Dentre um seleto e variado grupo de fungos, S. fimicola teve sua importância evidenciada como agente de decomposição em serapilheira nos EUA por Brow (1995).

Os sintomas inicialmente detectados na amostra submetida ao isolamento não apresentavam sinais (Figura 1) superficiais nos tecidos lesionados entre a região doente e sadia - halos arroxeados (Figura 1), recortada e submetida à assepsia superficial para isolamento que resultou no isolado de Sordaria fimicola obtida. Antes do isolamento, as folhas coletadas de capim-massambará apresentaram manchas arroxeadas, que representaram as lesões iniciais e necrose partindo do ápice, seguidas de rompimento do tecido denominado de fendilhamento (Figura 1A). As lesões naturalmente observadas apresentaram formas irregulares e alongadas (devido morfologia foliar), de coloração marrom pálea circundada por halos arroxeados (Figura 1BC), tanto na face abacial como adaxial.

Quanto à hipótese de não patogenicidade em $S$. arundinacearum confirmada pelas três inoculações, confirmaram-se as afirmações de Alexopoulos e Mims (1979), que ressaltaram que este gênero trata-se de um fungo saprófito, que cresce decompondo material orgânico, podendo ser um candidato a processos de biorremediação de resíduos orgânicos ou utilizado como bioherbicida.

Não se tem registrado nenhum trabalho de uso de $S$. fimicola como agente de degradação de materiais vegetais com elevada relação $\mathrm{C} / \mathrm{N}$, somente para uso na agricultura visando redução da aplicação de herbicidas por meio de um método de isolamento de fungos fitopatogênicos em condições que desfavorecem a multiplicação e crescimento de saprófitos.

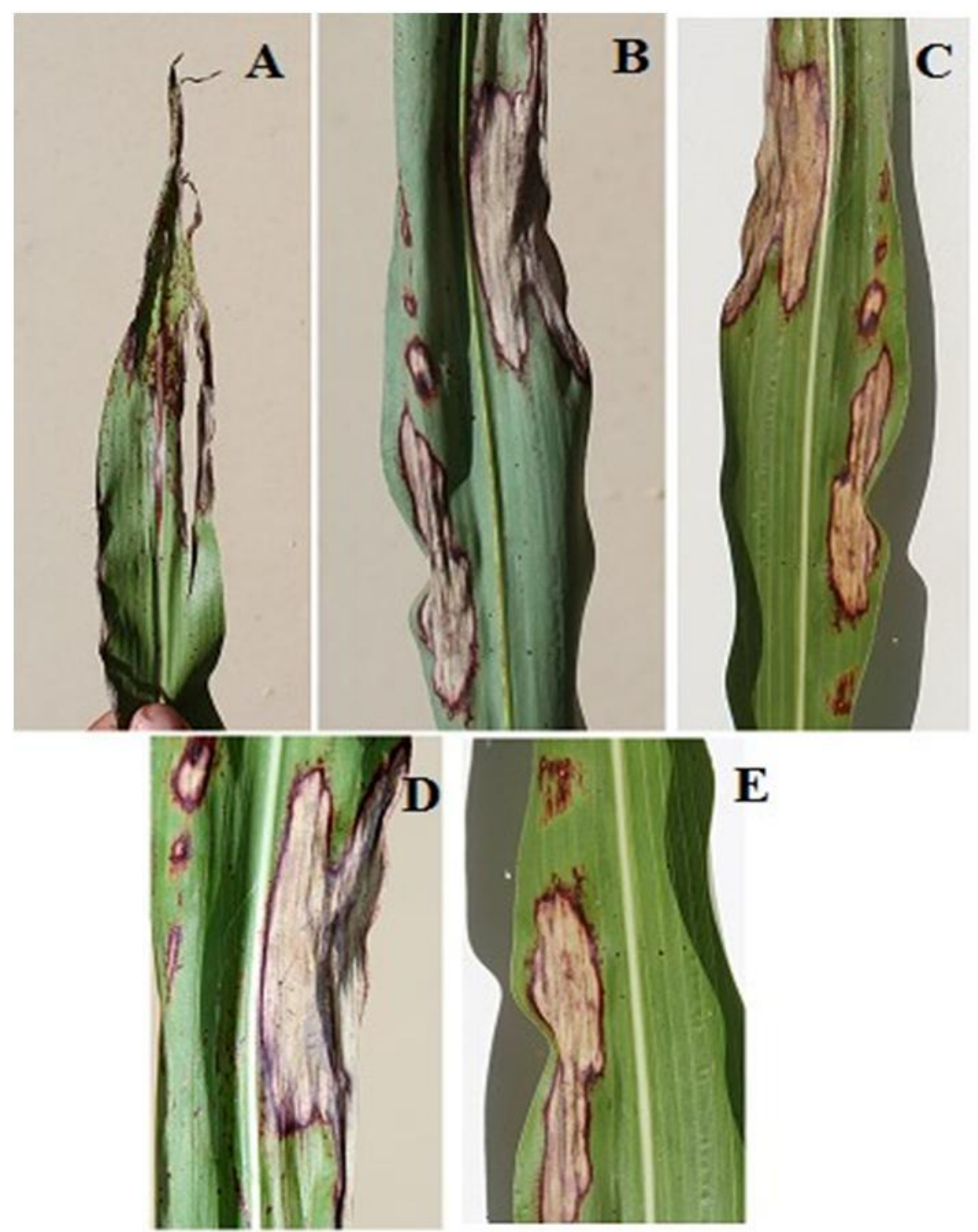

Figura 1. Aspectos sintomatológicos de folhas de capim-massambará. A. Manchas arroxeadas, necrose apical foliar e fendilhamento; B. Lesões necróticas irregulares e alongadas, de coloração marrom pálea com halos arroxeados na face abaxial; C. Lesões irregulares alongadas com halos arroxeados na face abaxial; D. Detalhe da forma da lesão; E. Lesão inicial e final arroxeada. 


\subsection{Teste fisiológico}

Ao teste $\mathrm{F}$ (teste de hipótese), somente no primeiro dia de crescimento após a inoculação, não se rejeitou a hipótese em unidade, havendo rejeição da hipótese de unidade para o diâmetro de colônia nos diferentes meios de cultura; nos dias dois, três, quatro, cinco, seis, sete, oito e nove rejeitou-se a hipótese de unidade. Ou seja, existe diferença significativa das médias do diâmetro de colônia de Sordaria sp. observadas nos diferentes meios de cultura. Não houve rejeição apenas no primeiro dia de avaliação, a hipótese de nulidade foi rejeitada nos demais.

No primeiro dia após a inoculação, não houve diferença significativa no crescimento micelial em diferentes meios de cultura. No segundo dia, maior crescimento foi verificado nos meios ST, BDA e AA (dois primeiros menor relação $\mathrm{C} / \mathrm{N}$ ). Do terceiro dia em diante, o maior desenvolvimento se manteve nos meios ST e BDA, diferindo-se estatisticamente dos demais meios. Somente no nono dia de crescimento observouse que a colônia fúngica atingiu a borda da placa de Petri (90 mm crescimento) (Figura 3). Ressalta-se que dentre os meios que não possibilitaram crescimento fúngico satisfatório (AA, NE e NA), o NA é específico para o crescimento de bactérias, o que justifica o fungo ter se desenvolvido com menor intensidade e menor quantidade de propágulos vegetativos. O meio de cultivo ST, que é amplamente utilizado para cultivo do falso fungo Phytophthora sp. (Jeffers e Martin, 1986), para Sordaria fimicola apresentou-se de forma similar ao BDA, podendo ser recomendado para utilização.

Rejeitou-se a hipótese de nulidade o parâmetro taxas de crescimento micelial (TC, mm.dia ${ }^{-1}$ ) e AACPCM, ou seja, existe diferença significativa das médias da TC. A maior taxa de crescimento mm.dia ${ }^{-1}$ ocorreu nos meios de cultura BDA e ST (Figura 2). Estatisticamente, as maiores taxas de crescimento micelial $\left(\mathrm{mm}_{\mathrm{dia}}{ }^{-1}\right) \mathrm{e}$ AACPCM foram observadas quando o isolado de Sordaria fimicola apresentou a menor atividade fisiológica no meio utilizado incubado sob o meio de cultivo BDA e ST, havendo estatisticamente para bactéria NA. O meio Neon não permitiu crescimento artificial deste ascomiceto detectado (Figura 2), por se tratar de um meio seletivo e exclusivo para crescimento de S. sclerotiorum.

As maiores atividades fisiológicas e artificiais do crescimento micelial de Sordaria fimicola foram observadas nos meios ST e BDA (Figura 3). A constituição química desses meios apresentam maiores concentrações de $\mathrm{C}$ e $\mathrm{N}$, elementos essenciais para a nutrição e desenvolvimento de fungos (Tortora et al., 2000). Hall (1971) estudou taxas de uso de $\mathrm{C}$ e $\mathrm{N}$ e sua conversão na atividade progresso do crescimento micelial de $S$. fimicola, observando os mesmos resultados verificados nas Figuras 2 e 3 .
Comparativamente em posição intermediária, o meio de cultivo AA (ágar-água) sem nutriente (sem fonte química de $\mathrm{C}$ e $\mathrm{N}$ ) apresentou crescimento micelial. $\mathrm{O}$ meio AA, devido ao fato de selecionar populações contaminantes de fungos fitopatogênicos em isolamentos de tecidos, é considerado seletivo (Agrios, 1997), no entanto, a quantidade de propágulos produzidos e sua velocidade de crescimento é menor. Conceitualmente, Sordaria sp. é considerado um fungo saprofítico (Alexopoulos e Mims, 1979), e este seria favorecido em meios de cultura ricos em $\mathrm{C}$ e $\mathrm{N}$, havendo pouco crescimento em meios de cultura pobres, o que atingiu um patamar de crescimento micelial intermediário (Figura 3).

As formas sexuadas como do grupo dos ascomicetos crescem e esporulam melhor em meios pobres, pois são estimulados por essa condição adversa como uma estratégia de sobrevivência e perpetuação da espécie, pois quando produzem esporos com variabilidade genética, estes servem para enfrentamento das inúmeras condições adversas no substrato (Ni et al., 2011). As fases assexuadas do ciclo ou a formação de micélio são mais frequentemente observadas em meios de cultura ricos em $\mathrm{C}$ e $\mathrm{N}$, havendo pouca formação para alguns gêneros inclusive de conídios assexuais (Bergamin Filho et al., 1995; Blum et al., 2006).
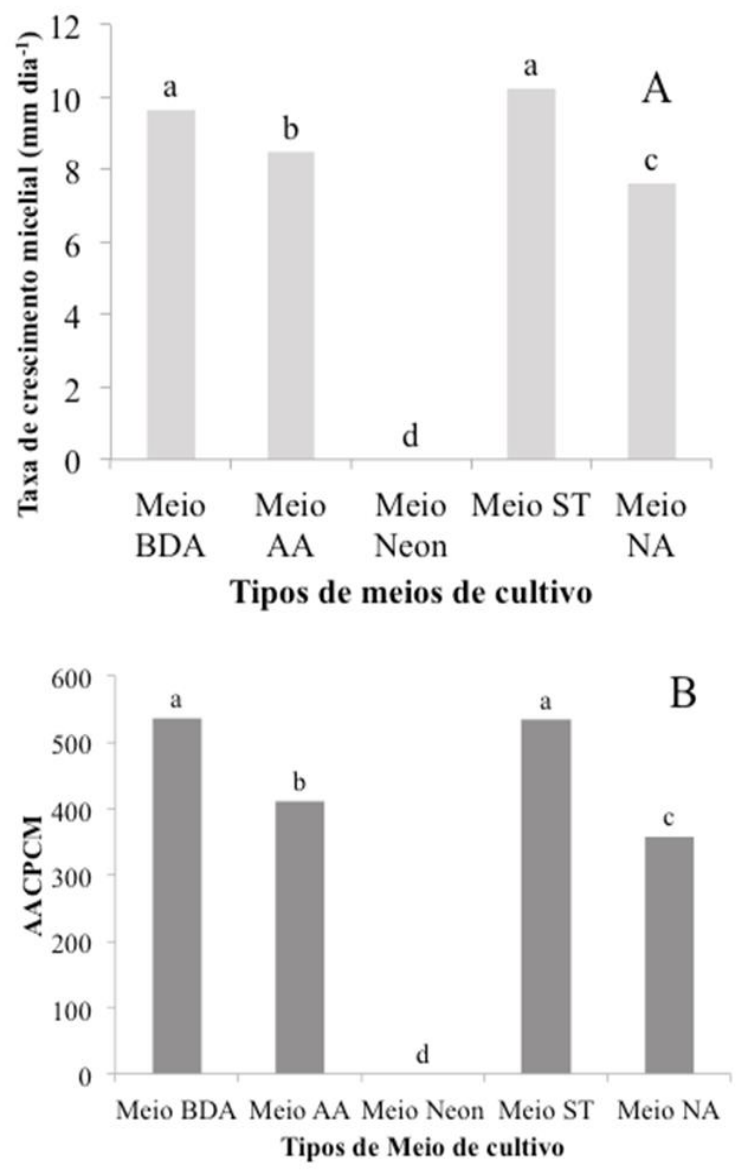

Figura 2. Médias da taxa de crescimento $\left(\mathrm{mm} \cdot \mathrm{dia}^{-1}\right)$ e da área abaixo da curva de progresso do crescimento micelial (AACPCM) após um período de avaliação de 10 dias em diferentes meios de cultivo. 


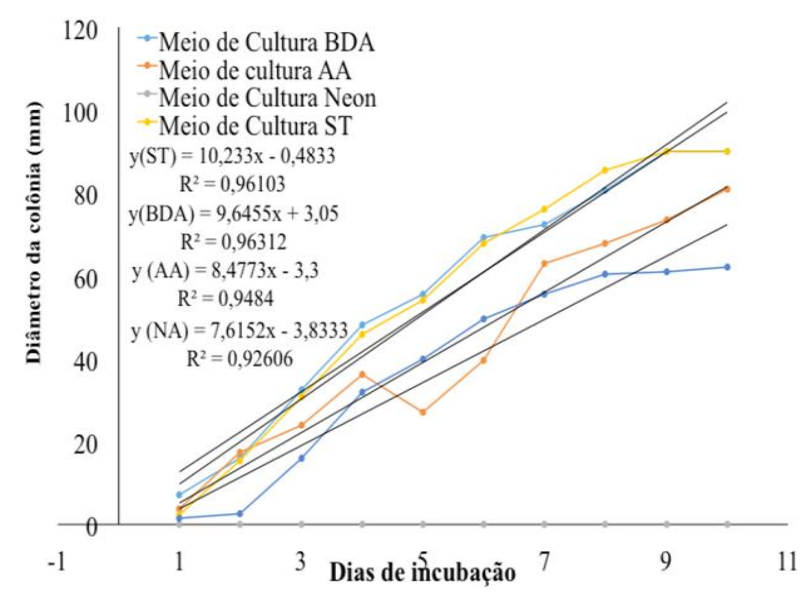

Figura 3. Curvas de crescimento micelial do isolado de Sordaria sp. oriundo de manchas foliares de capimmassambará em diferentes meios de cultura.

Neste ensaio, o meio de cultura NE (Neon) classicamente utilizado para deteç̧ão de Sclerotinia sclerotiorum não permitiu o crescimento de Sordaria sp., provavelmente porque este ascomiceto não produz nas condições artificiais o ácido oxálico como descrito por Napoleão et al. (2006), pois mudaria da coloração azul para um halo amarelo circundante ao micélio, mesmo com mínimo desenvolvimento micelial (Figura 3). A respeito do meio de cultura NA clássico para crescimento bacteriano (Basu et al., 2015), promoveu a menor curva de crescimento, provavelmente porque os componentes presentes no meio de cultura favorecem o crescimento de bactérias e não de fungos (Figura 3).

\subsection{Caracterização morfológica e morfométrica}

Caracterização de Sordaria sp. (teleomorfo): o isolado obtido em meio de cultura BDA apresentava micélio flocoso, pouco elevado, de coloração acinzentada (Figura 4AB), peritécio globoso, cônico a piriforme, imerso no substrato, gregário, semi-imerso no meio de cultura (Figura $4 \mathrm{AB}$ ), tendo desenvolvido tecido estromático liso e reticulado (Figura 4I), com dimensões de 1946,3-(1351,0)-507,9 x 1131,4-(828,2)$86,4 \mu \mathrm{m}$, base arredondada, o ostíolo apresentou dimensões de 413,85-(257,8)-123,8 $\mu \mathrm{m}, \quad$ o rostro algumas vezes ausente (Figura 4CFG), constricto ou conóideo (Figura 4DE), alongado (Figura 4HJ), espesso e curvo.

A asca unitunicada (Figura 5AB), cilíndrica (Figura 5B) à clavada, rostrada, região apical truncada hialina (Figura 5AB) (liberação de ascósporos); com oito ascósporos por asca, apresentou dimensões de 95,0(167,8)-135,6 x 21,8-(16,8)-9,1 $\mu \mathrm{m}$.

Os ascósporos apresentaram forma elipsoide à ovoide (Figura 5CDEF), com pouca variação morfológica, unisseriados na asca, com dimensões de 29,7-(22,6)-13,7 x 14,9-(10,9)-1,6 $\mu \mathrm{m}$, de coloração marrom-oliváceo a enegrecido (Figura 5CDEF), não apresentando ornamentação nem septação, sendo observada uma fenda longitudinal de centro oleoso com núcleo hialino (Figura 5EF).

O comprimento (C) do peritécio (Figura 6A) variou de $1047,0 \mu \mathrm{m}$ a $1767,0 \mu \mathrm{m}$, com valor de $1587,0 \mu \mathrm{m}$ mais frequente. Já a largura (L) do peritécio variou de 740 a $1100 \mu \mathrm{m}$, sendo a largura mais frequente representada por $870 \mu \mathrm{m}$ (Figura 6B). Estas foram as amplitudes mais frequentes observadas na população. Não apresentaram distribuição normal, o C e a L são tendenciosos e sua variação desqualifica como característica taxonômica para definição da espécie de Sordaria sp., sendo apenas um critério descritivo.

A partir da amostra analisada, observou-se que a asca não apresentou Distribuição Normal (C e L), com amplitudes variáveis de $\mathrm{C}$ de $165 \mu \mathrm{m}$ a $180 \mu \mathrm{m}$ (Figura 6C), e L de $14 \mu \mathrm{m}$ a $22 \mu \mathrm{m}$ (Figura 6D), sendo as medidas mais frequentes 180 e $19 \mu \mathrm{m}$, respectivamente.

As dimensões dos ascósporos apresentaram Distribuição Normal com amplitudes mais frequentes do C entre 20 e $27 \mu \mathrm{m}$ (Figura 6E), e largura de 10 a $14 \mu \mathrm{m}$ (Figura 6F), sendo as médias mais frequentes as medidas de 25 e $11 \mu \mathrm{m}$, respectivamente. $\mathrm{O}$ diâmetro do ostíolo apresentou Distribuição Normal com amplitude ocorrendo entre 160 a $300 \mu \mathrm{m}$ de diâmetro (Figura 6G). A análise morfométrica e morfológica de estruturas reprodutivas representa um importante critério de identificação e reconhecimento de táxons fúngicos (Alexopoulos e Mims, 1979).

A possibilidade de investigação de Sordaria sp. como um possível decompositor de material orgânico de S. arundinaceum pode ser uma estratégia de aplicação e uso. Para as espécies S. bicolor (sorgo comercial) e $S$. halepense, bastante cultivada (primeira) e infestante nos campos de produção (segunda) brasileiros, foram utilizados os fungos Drechslera gigantea, Exserohilum longistratum e E. rostratum como agentes de controle biológico desta planta espontânea nos EUA (Chandramohan e Charudattan, 2011). 


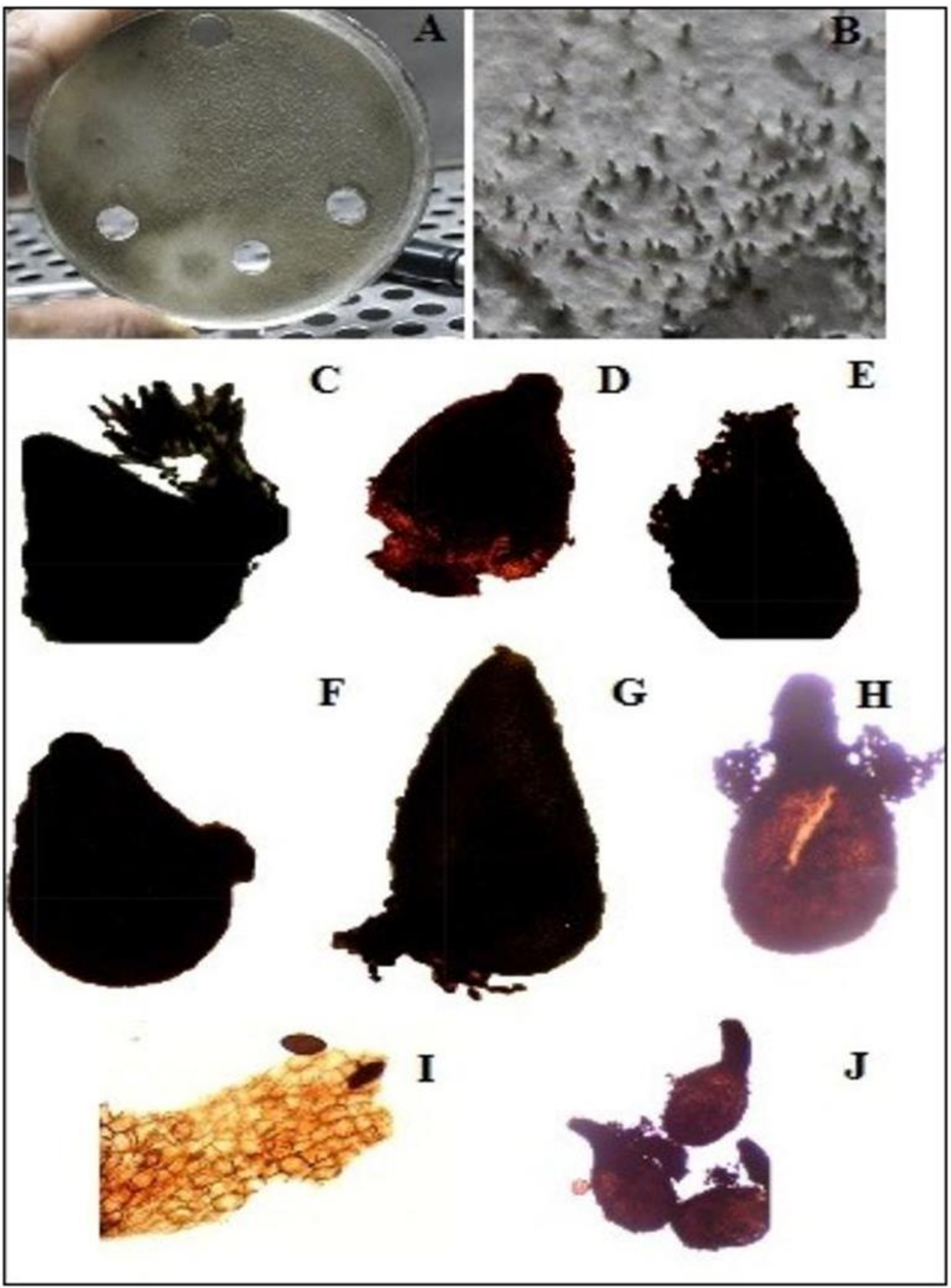

Figura 4. Aspectos morfológicos da cultura e do peritécio de Sordaria sp. isolada de folhas de capim-massambará (Sorghum arundinaceum). A. Cultura micélio flocoso, pouco elevado de coloração acinzentada; B. Detalhe da superfície micelial do peritécio em cultura demonstrando elevação do rostro; C. Peritécio de rostro curto e formato cilíndrico e base arredondada; D. Peritécio de base arredondada e rostro constrito; E. Rostro enegrecido de base arredondada de forma clavada; F. Peritécio de base arredondada, superfície lisa, rostro pouco evidente; G. Peritécio de corpo alongado, rostro pouco evidente; H. Peritécio de base elíptica ovoide e rostro proeminente e alongado; I. Superfície do tecido peritecial formando células angulares enegrecidas; J. Vários peritécios de forma elíptica e rostro proeminente. 


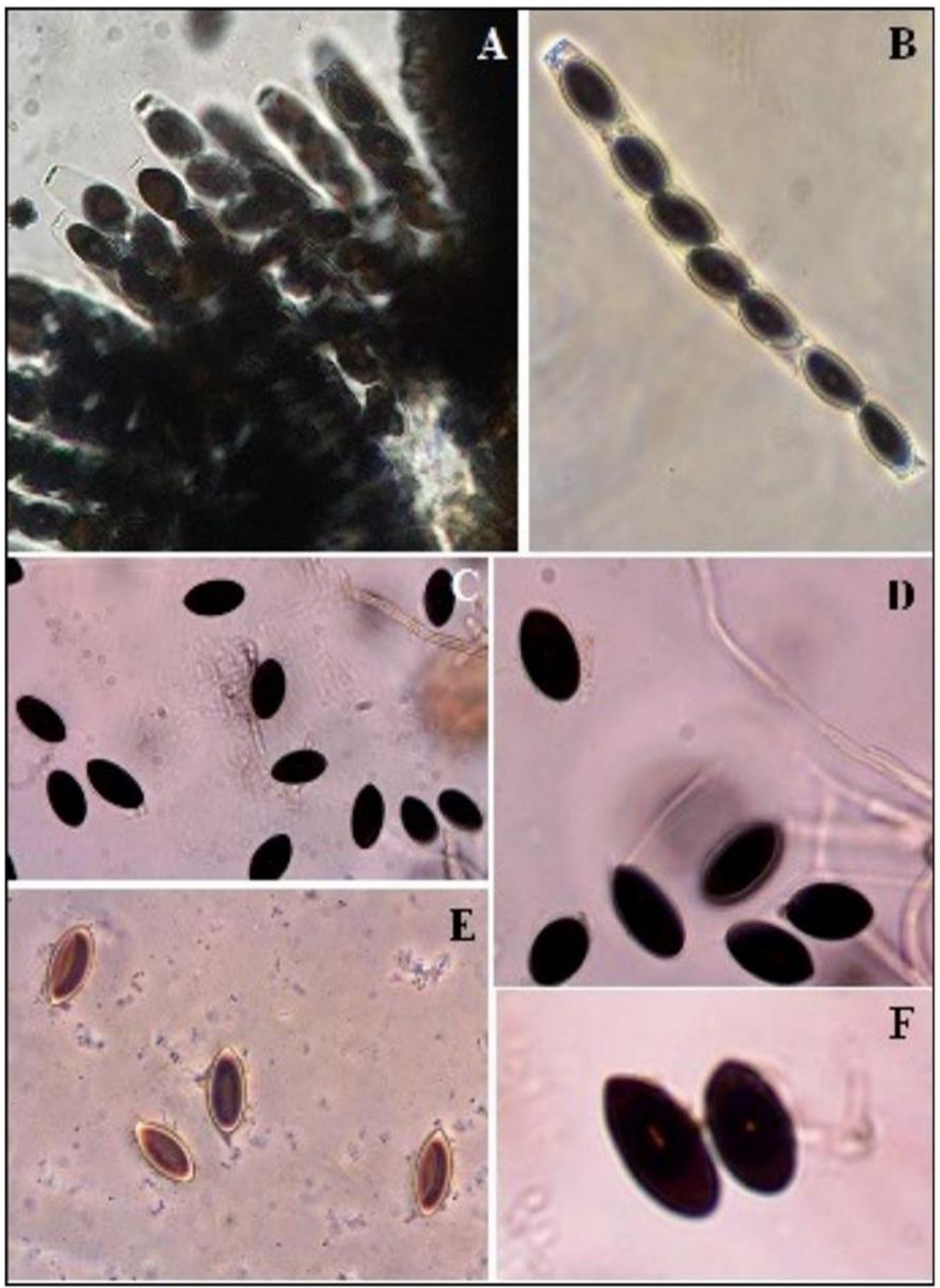

Figura 5. Aspectos morfológicos da asca e ascósporos de Sordaria sp. isolada de folhas de capim-massambará (Sorghum arundinaceum). A. Ascas unitunicadas contendo conjuntos de oito ascósporos; B. Detalhe da asca contendo sete ascósporos com detalhe na região apical truncada hialina de liberação de ascósporos; C. Ascósporos de formato elíptico enegrecido; D. Detalhe dos ascósporos de forma elíptica com pouca variação morfológica; E. Ascósporos de coloração marrom, em microscopia de contraste de fase de forma elíptica e enegrecida; F. Detalhe dos ascósporos apresentando, na região mediana com gútula transparente. 

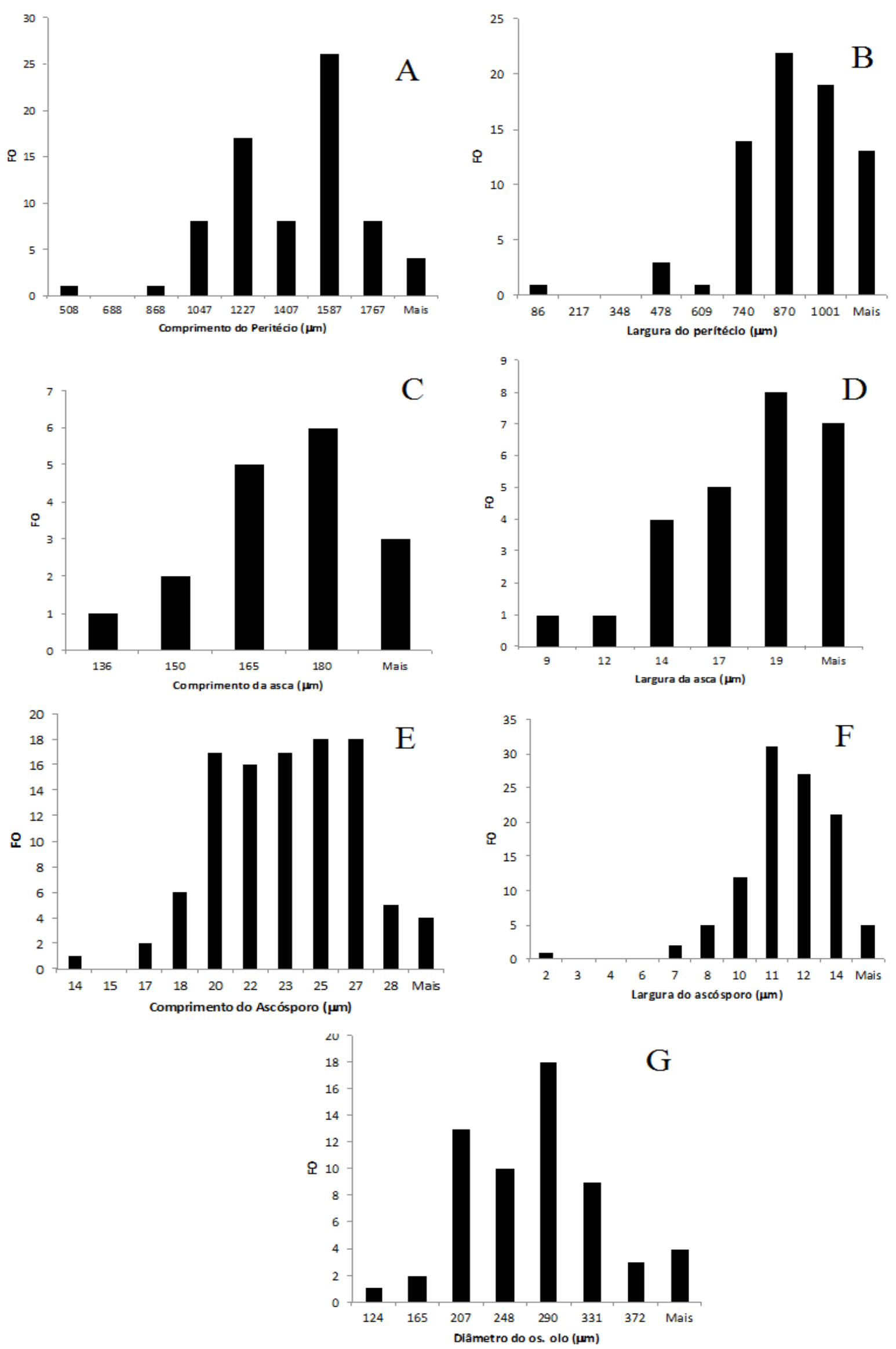

Figura 6. Frequência observada (FO) de dimensões de Sordaria sp. A. Comprimento do peritécio; B. Largura do Peritécio; C. Comprimento da asca; D. Largura da asca; E. Comprimento do Ascósporo; F. Largura do Ascósporo; G. Diâmetro do ostíolo. 


\section{Conclusões}

O isolado de Sordaria obtido de folhas de capimmassambará não foi patogênico em testes artificiais de inoculação em folhas, tanto pelo método de disco de micélio como solução de ascósporos.

O meio de cultura ideal para crescimento micelial deste isolado foi ST e BDA.

Com base nas características morfológicas e morfométricas, o isolado foi identificado como sendo $S$. fimicola sensu Roberge.

As médias de comprimento e largura dos ascósporos e o diâmetro do ostíolo representaram os valores mais confiáveis para fins taxonômicos.

Este é o primeiro registro de ocorrência de Sordaria sp. em uma espécie de sorgo no Brasil.

\section{Referências Bibliográficas}

Agrios, G.N., 1997. Plant pathology, fourth ed. Academic Press, St. Paul, USA, 606 p.

Alexopoulos, C.J., Mims, C.W., 1979. Introductory mycology, Third ed., John Wiley, New York, USA, p. 632.

Alfenas, A.C.A., Mafia, R.G., 2007. Métodos em fitopatologia. Editora UFV, Viçosa, 382 p.

Barnett, H.L., Lilly, V.G., 1947. The effects of biotin upon the formation and development of perithecia, asci, and ascospores by Sordaria fimicola. Ces: and the not. Ces: and the not. American Journal Botany, 34(4), 196-204.

Basu, S., Bose, C., Ojha, N., Das, N., Das, J., Pal, M., Khurana, S., 2015. Evolution of bacterial and fungal growth media. Bioinformation, 11(4), 182-184.

Bergamin Filho, A., Kimati, H., Amorim, L., 1995. Manual de Fitopatologia: princípios e conceitos, terceira ed. Editora Agronômica Ceres Ltda, São Paulo, v.1, 919 p.

Blum, L.E.B., Cares, J.E., Uesugi, C.H., 2006. Fitopatologia o estudo das doenças de plantas, segunda ed. Otimismo, Brasília, Brasil, n. 2, 121 p.

Brow, G.G., 1995 How do earthworms affect microfloral and faunal community diversity? Plant and Soil, 170(1), 209-231.

Carr, A.J.H., Olive, L.S., 1958. Genetics of Sordaria fimicola. American Journal Botany, 45(2), 142-150.

Chandramohan, S., Charudattan, R., 2001. Control of seven grasses with a mixture of three fungal pathogens with restricted host ranges. Biological Control, 22(4), 246-255.

Chiang, M., Van Dyke, C.G., Chilton, W.S., 1989. Four foliar pathogenic fungi for controlling seedling Johnsongrass (Sorghum halepense). Weed Science, 37(6), 802-809.
Doguet, G., 1960. Morphologie, organogénie et evolution nucléaire de l'Epichloe typhina. La place des Clavicipitaceae dans la classification. Bulletin Society Mycological, 76(1), 171-203.

Greis, H., 1938. Entwincklungschit on Sordaria fimicola (Rob). Botany Archieves, 38(1), 113-15.

Greis, H., 1942. Mutations und Isolationversuche zur Beeinflussung des gescheletes von Sordaria fimicola (Rob). Zeitschrift Botany, 89(1), 341-353.

Hall, R., 1971. Effect of carbon-nitrogen ratios on production of perithecia by Sordaria fimicola. Canadian Journal of Microbiology, 17(1), 132-134.

Ingold, C.T., 1956. The spore deposited of Daldinia. Transitions British Mycology Society, 39(1), 378-380.

Ingold, C.T., Cox, V.J., 1955. Periodicity of spore disharge in Daldinia. Annuals Botany Nova Scotia, 19, 210-219.

Jeffers, S.N., Martin, S.B., 1986. Comparison of two media selective of Phytophthora and Pythium species. Plant Disease, 70, 1038-1043.

Lorenzi, H., Matos, F.J.A., 2008. Plantas daninhas do Brasil, nativas e exóticas, quarta ed. Instituto Plantarum de Estudos da Flora Ltda., Nova Odessa, p. 640.

Ni, M., Feretzaki, M., Sun, S., Wang, X., Heitman, J., 2011. Sex in fungi. Annual Review Genetical, 45, 405-430.

Olive, L.S., 1956. Genetics of Sordaria fimicola I. Ascospore color mutants. American Journal Botany, 43(1), 97-106.

Panizzi, R.C., Fernandes, N.G., Camargo, M., 2005. Doenças do sorgo, in: Kimati, H., Amorim, L., Rezende, J.A.M., Bergamin Filho, A., Camargo, L.E.A., (Eds.), Manual de Fitopatologia. Editora Ceres, São Paulo, v. 2, pp. 597-606.

Ritchie, P., 1937. The morphology of the perithecium of Sordaria fimicola (Rob) Ces. and the not. Journal Elisha Mitchell Scientific Society, 53(2), 334-342.

Tortora, J.G., Funke, B.R., Case, C.L., 2000. Microbiologia, sexta ed. Artmed, Porto Alegre, 920 p.

Zhang, W.M., Moody, K., Watson, A.K., 1996. Responses of Echinocloa species and rice (Oryza sativa) to indigenous pathogenic fungi. Plant Distribution, 80(9), 1053-1058.

Zhang, W.M., Watson, A.K., 1997. Effect of dew period and temperature on the ability of Exserohilum monoceras to cause seedling mortality of Echinocloa species. Plant Disease, 81(6), 629-634. 